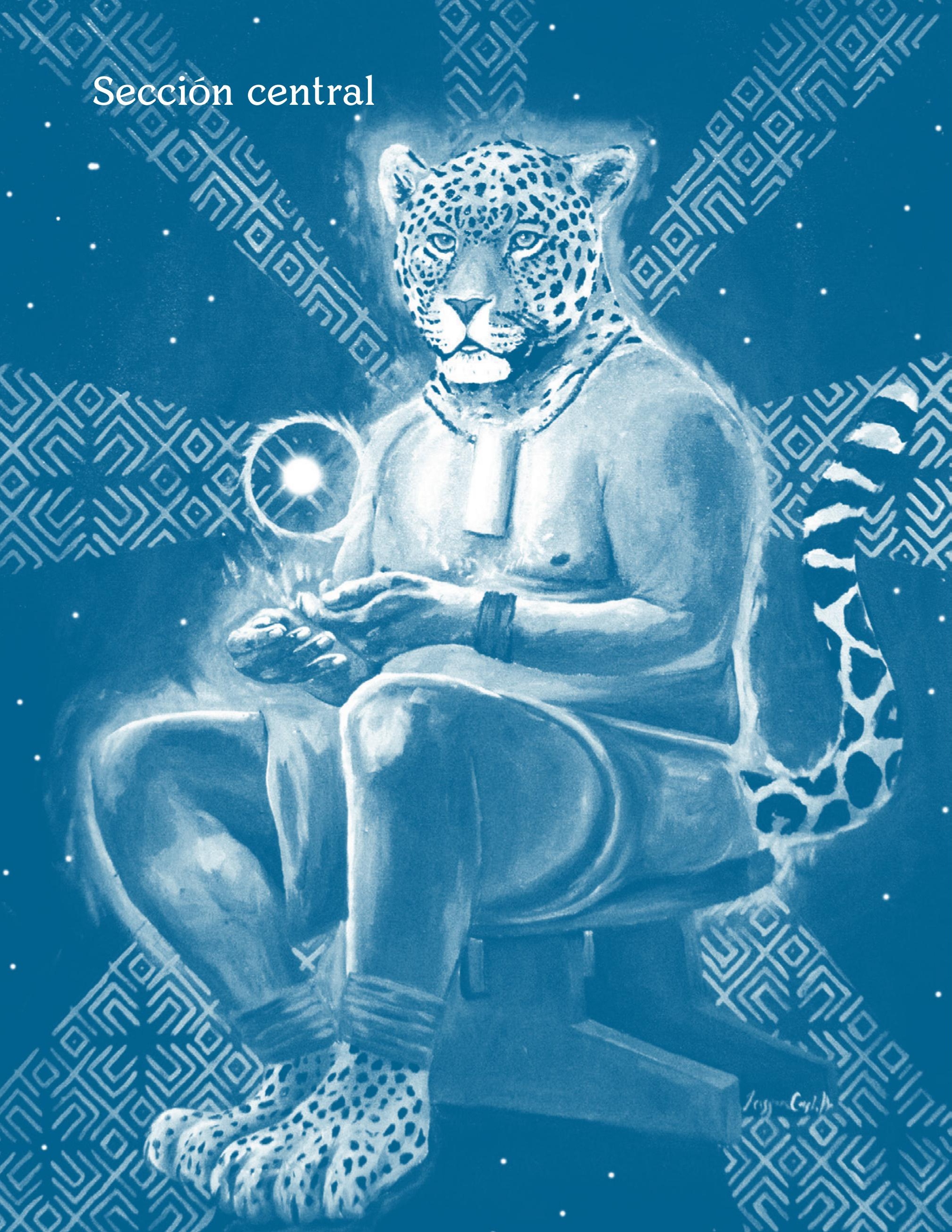




\section{Enlaces globales y link del antepasado: ante dos pinturas de un visionario de izquierda}

\section{Artículo de reflexión}

Recibido: 20 de abril de 2018

Aprobado: 10 de mayo de 2018

\section{Bruno Mazzoldi}

Investigador independiente, Colombia

mataplata@yahoo.com

Cómo citar este artículo: Mazzoldi, Bruno (2018). Enlaces globales y link del antepasado: ante dos pinturas de un visionario de izquierda. Estudios Artísticos: revista de investigación creadora, 4(5) pp. 206-214. DOl:https://doi. org/10.14483/25009311.13494
Nacimiento de Ka' mari, primer jaguar. (Jeisson Castillo, 2018). Óleo y tabaco sobre lienzo, 140 × 90 cm. Cortesía del artista.

\section{Resumen}

Sea desde el Foro Económico Latinoamericano, sea desde los soberbios monumentos de las Luces parisinas proliferan enlaces que deberían reconciliar a los maestros verdes de la Amazonía con la modernidad de la postmodernidad y relativos avances de corte franciscano. Ante semejantes abrazos no sobra atisbar las argucias y el indómito recato de lo cotidiano emergente de las visiones de Jeisson Castillo, pintas y pinturas del golpe de sin-estado escurrido a expensas de sujetos soberanos por intercesión del compuesto farmacológico conocido como "ayawaska", rituales de gloriosa modestia a la altura de la caza amorosa declarada a una astronave de flores, comunión de caminos irreductibles a la disyuntiva de emancipación o captura porque reacios al éxtasis que suele desdeñar la historia, si acaso sabiduría y arrugas de los pies de la Madre del Jaguar insinuados en chancletas de caucho contemporáneo, más sólidas y actuales que la sandalia escupida por el atanor de Empédocles.

\section{Palabras clave}

Francisco, Ayawaska, Maculada Concepción.

\section{Global Links and the Ancestor Link: Facing Two Paintings from a Left- Leaning Visionary}

\footnotetext{
Abstract

$\mathrm{Be}$ it from the Latin American Economic Forum, or from the superb monuments of the Parisian Lights, links proliferate that should reconcile the green masters of the Amazon with the modernity of postmodernity and the relative advances of a franciscan nature. Facing such embraces, there is
} 
still need to glimpse the tricks and the indomitable modesty of the everyday life which emerges of the visions of Jeisson Castillo, pintas and paintings of a drained stateless coup at the expense of sovereign subjects through the intercession of the pharmacological compound known as "ayawaska". Rituals of glorious modesty at the height of the amorous hunt declared to a flowered spaceship, communion of irreducible paths to the dilemma of emancipation or capture, because they are reluctant to the ecstasy that usually disdains history, if only wisdom and wrinkles of the feet of the Mother of the Jaguar, as insinuated in contemporary rubber flip flops, more solid and current than the sandal spit by Empedocles' athanor.

\section{Keywords}

Francisco, ayawaska, Maculate Conception.

\section{Liens mondiaux et le lien de l'an- cêtre : devant deux tableaux d'un visionnaire de gauche}

\section{Résumé}

Soit-il du Forum économique latino-américain, ou des superbes monuments des Lumières parisiennes, il en prolifère des liens qui devraient concilier les maîtres verts de l'Amazonie avec la modernité et postmodernité et les relatifs progrès de type franciscain. Face à ces étreintes, on n'épargnera entrevoir les arguties et la modestie sauvage du quotidien qui émerge des visions de Jeisson Castillo, des pintas et des peintures du coup-sans-état qui se passe au détriment des sujets souverains par l'intercession du composé pharmacologique connu sous le nom « Ayawaska ». Rituels de modestie glorieuse à la hauteur de la chasse aimante déclarée à un vaisseau spatial fait de fleurs, communion de chemins irréductibles au dilemme d'émancipation ou de capture, parce que réticents à l'extase qui dédaigne l'histoire, ou, en tout cas, la sagesse et les rides des pieds de la Mère du Jaguar, insinuées en des flip flops en caoutchouc contemporain, plus fortes et courantes que la sandale qui fut crachée par l'athanor d'Empédocle.

\section{Mots clés}

Francisco, Ayawaska, Conception Maculée.

\section{Conexões globais e link ancestral: diante de duas pinturas de um visionário da esquerda}

\section{Resumo}

Seja desde o Fórum Econômico Latino-Americano ou desde os monumentos soberbos das Luzes parisienses, proliferam elos que deveriam conciliar os mestres verdes da Amazônia com a modernidade da pós-modernidade e os avanços relativos de uma natureza franciscana. Diante de tais abraços, não há necessidade de vislumbrar os truques e a modéstia indomável do cotidiano emergente das visões de Jeisson Castillo, pintas e pinturas do golpe de sem-estado drenado às custas de sujeitos soberanos pela intercessão do composto farmacológico conhecido como "ayawaska", rituais de gloriosa modéstia à altura da caça amorosa declarada a um navio de flores, comunhão de caminhos irredutíveis à disjuntiva de emancipação ou captura, uma vez relutante ao êxtase que sói desdenhar a história, se acaso sabedoria e rugas dos pés da Madre del Jaguar insinuam-se nas sandálias de borracha contemporâneas, mais sólidas e atuais do que aquelas fundidas pelo atanor de Empédocles.

\section{Palavras-chave}

Francisco, Ayawaska, Maculada Concepción.

\section{Iskai ruraikuna sug mimanda ruraska}

\section{Maillallachiska}

Kai kilkapi parlanakumi imasam iachakuna kawachikuna rurangapa allilla kausangapa $\mathrm{i}$ kawangapa imam rukanchi Nukanchipa atun llagta amazonia sutipi llukanchimi allilla iuiaringa mana tukuringapa nukanchi llukaska suma kausai iachachiska u iachaikuska Nukanchipa pacha mama.

\section{Rimangapa Ministidukuna}

Francisco chasa suti kari, ayawaska, mamitica chasa suti. 
La tribu indígena Yawanawa mostró hoy [16 Mar 2018] en el Foro Económico Latinoamericano de Sao Paulo sus ritos locales, entre ellos el de la Ayahuasca, a través de un documental que usó tecnología avanzada para contar las tradiciones centenarias de este pueblo del corazón de la Amazonía. (EFEverde, 2018)

La obra Awavena, de la directora Lynette Wallworth, se ha convertido estos días en uno de los atractivos visuales al mostrar por medio de técnicas de realidad virtual 3D algunas prácticas medicinales de esta tribu, que se concentra en el estado brasileño de Acre (noreoeste), aunque también está afincada en Perú y Bolivia.

"Es para que las personas tengan el privilegio de viajar hasta la aldea sin salir del lugar usando la sofisticada tecnología del hombre blanco", dijo a Efe el líder indígena Tashka Yawanawa.

Rodeado de hombres vestidos de trajes impolutos, el jefe de la tribu cuenta que para quien nunca tomó Ayahuasca o alguna otra "medicina" basada a partir de plantas de la cuenca amazónica al visualizar la pieza verá "la misma cosa como si lo estuviera tomando en un vaso".

\section{El Espectador}

En la tele, la semana pasada un exuberante desquite de armazones amazónicas, Arco de Triunfo, Gare du Nord y Torre Eiffel parasitadas por dédalos de verdor digital y micos onomásticos correspondientes a los padrinos y madrinas de las matas ad hoc: One Heart One Tree, edificante mega-instalación de Naziha Mestaoui («http://www.seedoflight. fr»), artista belga-tunecina promotora de las más exquisitas "tecnologías de la conexión" desde hace algunos años públicamente entregada a intervenciones estético-científicas de común acuerdo con los Kaxinawá del Brasil (grupo lingüístico pano), Huní Kuin y Ashaninka.

No cabría argüir (si de argüir apenas se tratase) que mientras sobran políticos llevados a remachar antiguas y nuevas fronteras poniendo en su imposible lugar a perseguidos de medio mundo no faltan representativos samaritanos dispuestos a refutarlas en aras de la compasión ecológica espectacular encaminándose hacia portales tan exóticos como el que otro representante mansamente encorvado está o estuvo en trance de franquear sonriendo, solideo y túnica de cándido brillo en contraste con la efusión cromática de los pueblos nativos para que el mayor número secunde la iniciativa ejemplar juntamente con quienes hace rato deberían haber dado muestra de querer adelantarse en pos del apretón recíproco aunque sea a la altura del anuncio de un paradero de buses: "Demos el primer paso // Francisco // Visita apostólica a Colombia 20171, pues hace rato los advenedizos del abrazo magnánimo deberían haber aparecido y comparecido, eternos segundones de lo transcrito en razón - muy determinada razón- de aquello que "propone una identidad facticia que da la medida del desfase [écart] entre la conversión y la iniciación, la que, obligatoriamente, siempre regala una identidad, modesta pero segura. (...) A partir de una situación de conquistado, de inferior por ende, el acercamiento del convertido se juega [se joue], como el del artista, ahí donde la mirada encuentra un objeto - Libro, columna de signos, memoria jeroglífica - y lo confronta con otros. La conversión consiste fundamentalmente en captar un objeto e intentar apropiárselo mediante representaciones" (Guidieri, 1987, pp. 160-161), en otros aproximativos términos se trataría y re-trataría del presunto compás retardatario de comunidades abiertas a otra experiencia del objeto, al expropiante acontecer de una semicosa sin oficio rentable no propiamente opuesta al sujeto, no del todo una ni producto de cualquier despelote del Todo en el cruce con la coyuntura aural del fetiche, esa "infinidad de ínfimos en que se divide, como polvareda, la historia misma" (Guidieri, p. 27), en el traslapo de laboratorio y oratorio, hábito trabajoso y atención implorante, umbral de lo animado y lo

1 Al dejar entender que el encuentro discretamente requerido debe privilegiar eventuales consensos, disensos o transacciones alrededor de la presumible amenaza del extractivismo, no por eso el párrafo 146 de la carta encíclica Laudato si' habría descartado amagos dialógicos de alcance otramente reivindicativo igualmente y principalmente comprometidos con las llamadas tradiciones culturales: "En este sentido, es indispensable prestar especial atención a las comunidades aborígenes con sus tradiciones culturales. No son una simple minoría entre otras, sino que deben convertirse en los principales interlocutores, sobre todo a la hora de avanzar en grandes proyectos que afecten a sus espacios." (S. S. Francisco, 2015, p. 126). Sin embargo, los asomos de fisonomías, atuendos, fórmulas de cortesía y diseños de accesorios pertinentes a la visita apostólica del año pasado no acompañaron conatos de interlocución merecedores de noticia, destacaron si acaso una ulterior fase evolutiva de la iconografía que suele celebrar a "los indios como adornos culturales" en armonía con el estilo hegemónico denunciado por la sociología de la imagen (Rivera, 2006, p. 145). 


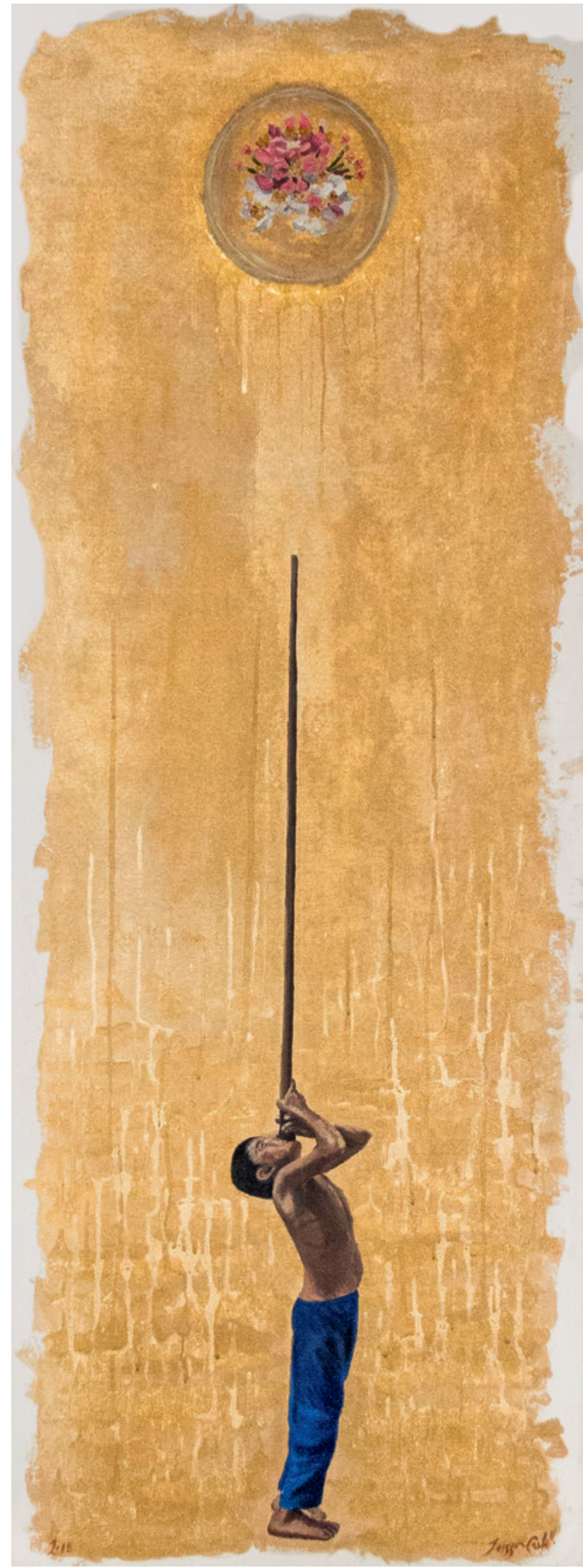

Cazando flores en territorio caapiniano. (Jeisson Castillo, 2018). Óleo, polvo de oro y acrílico sobre lienzo, 160 × $60 \mathrm{~cm}$. Cortesía del artista. 


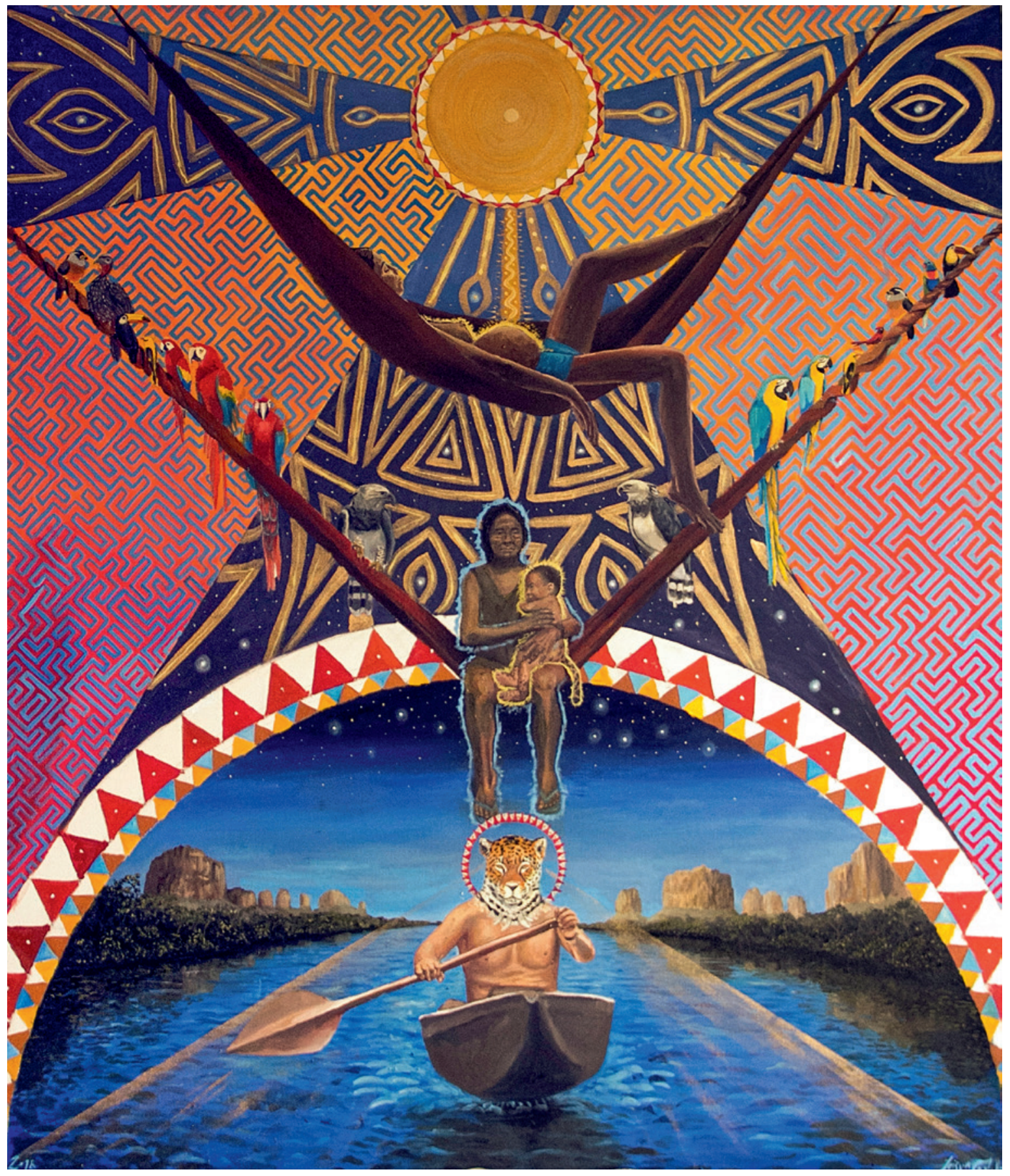

Nacimiento de Ka' mari, primer jaguar. (Jeisson Castillo, 2018). Óleo y tabaco sobre lienzo, 140 x $90 \mathrm{~cm}$. Cortesía del artista. 
inanimado circunscrito por el felpudo mercantil en vitrinas y pantallas de magia gris que entre las prácticas cultuales y las artísticas un versátil compadre de los habitantes de las islas Salomón y de los aborígenes australianos (cierto antropólogo ex-estructuralista harto del "arte de masa" en que se destierra la "politización del arte" auspiciada por Benjamin) bien pudo redimir por interpuesta grandilocuencia de un poeta revolucionario como Khlebnikov atento a "radios gigantes de los destinos de la humanidad, cuyas ondas son pobladas de humanos y cuya única pulsación dura siglos enteros" (Guidieri, p. 46), a lo mejor sintonizado con las ondas cerebrales emitidas en pleno canto chamánico huní kuin ya convertidas al paradigma del producto visible gracias a los tecnodispositivos de Mestaoui y al apoyo de la Fundación Cartier. Faltaría más.

Faltaría no perder de vista ni de otros sentidos la "tensión permanente entre las luchas por la transformación comunitaria emancipadora y las luchas por la inclusión social que nos reconocen y financian bajo condiciones de subordinación" (Almendra, 2017, p. 166), siempre o casi siempre que no se descuide la atrevida tentativa de verter por fuera de los códigos imperantes las nociones de "inclusión", "descuido" y "afuera" donde resta por consentir la pertinencia de la mensurabilidad del fuero de un sujeto individual o colectivo convencido de permanecer al control de sí mismo y del enfrentamiento de lo propio y lo alieno cuando se insinúa y dilata el desafuero visionario que algunos no dudan en considerar soberano.

Amén del empleo de la palabra "territorio" provisionalmente asociada con el destronamiento del ego o desterritorialización psicosomática inducida por el brebaje conocido como "ayawaska", uno de cuyos ingredientes imprescindibles viene a ser el tallo ondulante de la liana clasificada desde el siglo antepasado como Banisteriopsis caapi, tomen (es un decir) Cazando flores en territorio caapiniano (2018, óleo, polvo de oro y acrílico sobre lienzo, $160 \times 60 \mathrm{~cm}$.): echada atrás la cabeza, las manos unidas apretando muy cerca de la embocadura del arma, con aplomo infalible el niño sostiene en equilibrio sobre los labios una cerbatana tan firme y tan graciosamente recta hasta dar fe al mito y al rito recién venidos capaces de traducir el arma en una perfecta extensión de la columna vertebral de manera que el invisible virote envenenado por exceso de dulzura venga a ser beso soplado hacia una esfera de flores cenitales no menos luminosas que evanescentes, sépalos y pétalos rosados y níveos, brotes esquivos de la enredadera serpentina que entrega su nombre al pretendido coto de caza, íntimo y remoto blanco del cazador paradóiico.

Trastulo por ende, no arma propiamente dicha y agarrada para perseguir y sacrificar, máxime entreteniendo el cortinaje dorado que substituye, revela e induce roces de hojas, ramas y sotobosque sin las veleidades libertarias de un dripping que se las dé de salvaje. Apenas pequeñas gotas de alquimia azarosa, incontables. De ninguna manera para sospechar que Jeisson Castillo pretendería convertir la selva al encanto de orfebrerías inocuas.

Enredada si acaso la vigencia de la preposición para y el modo de su finalismo sin fin cuando el acecho y la secuencia, lo sagrado y el sacrificio están otramente de por medio, soslayadas consabidas categorías y códigos resabiados del sentido más conveniente a los conteos y cuentos del Logos, contabilidad del antiguo Verbo y modernísimas mudas del New Brand Mismo, donde carne y hueso siguen corriendo riesgos de teleseries por andar sumisos a la ontoteología del poder clavado en lo igual imperante mientras el sacrosanto asedio responde a los ecos del baile que retumba por más de una pinta, por una sola cada vez más de una en aras del agotamiento de la compacidad unaria no exactamente para dilatar la equivalencia de substitución y desvelamiento del espesor vegetal enmascarado y verificado tras oro atmosférico, más que exactamente: "En cierta manera la máscara representa y, de hecho, efectúa, paradójicamente, el desenmascaramiento de los animales, que gracias a ella se pueden aparecer en la maloca como los humanos que ellos conciben que son, desde su perspectiva, quitándose así, temporalmente durante el baile, el 'vestido' animal que define la relación entre otras especies y el homo sapiens, y que articula la perspectiva de éste. Vemos que el ser animal o ser humano es un asunto relacional y no corresponde a una metafísica de la fijeza inmutable." (Duchesne, 2017, p. 106)

Por si algún titubeo en cuanto a máscaras desenmascaradoras (dignas de satisfacer la urgencia 
de alguna justificación del prefijo des- hoy tan en boga, una que escape a los dualismos de poner/ quitar y construir/destruir dictados por la lógica celosa de lo propio) asístase al Nacimiento de Ka'amari. Primer Jaguar (2018, óleo y tabaco sobre madera, 140 x $90 \mathrm{~cm}$.): Maculada Concepción quizás menos traducible a las vallas del Pneuma cristiano que a las márgenes del Soma védico, la redondez fervorosa del vientre de la joven absorta en el chinchorro de arriba hospeda el semen emanado de la redondez pletórica del Sol que la cubre.

La mano derecha de la amante del astro está suspendida sobre el chinchorro de abajo y las puntas de los dedos del pie colgante alcanzan a rozar el hamaqueo siguiente insinuando la continuidad de los registros narrativos sucedáneos y simultáneos pues (hay que saberlo más allá de lo que por saber suele saberse) lo pintado encarna al mito como tan solo sabría la liturgia del pincel.

Es así que ambas hamacas manifiestan una sola acogida convergente. El vértice del triángulo de la segunda coincide con la severa mujer que carga a un recién nacido de garras y cola manchadas como Sol manda. A sus lados dos águilas-arpías (Harpia harpyja) de ceño esplendoroso y adusto, guacamayas, tucanes y toda suerte de aves anidan en los brazos de la jeroglífica hamaca, notas picudas de pentagrama ornitológico. A bien mirar no resultan humanamente tejidos los extremos del balanceo intemporal. Encegueciendo mejor entre creer y crear los cabos de este chinchorro vienen a ser también las espirales del bendito bejuco.

En efecto los pies de la Madre sentada sobre el "link del antepasado" (imprudente versión de aya y waska, a oídos de quechuahablante "difunto" y "lazo") entonces y ahora pisan el azul profundo del firmamento hasta entregar la caricia de una chancla grisácea al aro glorioso que circunscribe la cabeza de Ka'amari, hocico de felino y rostro de humano hecho y derecho.

A través del registro mayor navega por ende y allende el Primer Jaguar. Empuña el remo inmerso en el aire no propiamente para que la canoa se deslice sin encrespar la avenida líquida cubierta por el semicírculo cósmico que amplifica los destellos rojos y blancos de su aureola bestial. Bajo la prora vertiginosa las aguas enmascaran un azul tan hondo cuanto el cielo nocturno.

Que el altisonante atributo "cósmico" no extravíe a nadie. No por nada los tránsitos entre las múltiples dimensiones del origen de Ka'amari, contactos sutiles porque trivialmente digitales, culminan en el vago halago de una chancleta demasiado común y corrida para dar la suela a nuestra todavía poco apoteósica carne de cada día en la intersección de las márgenes que no solamente los alquimistas occidentales reconocen como coincidencia de laboratorio y oratorio.

\section{Referencias}

Almendra Quiguanás, V. (2017). Entre la emancipación y la captura-Memorias y caminos desde la lucha Nasa en Colombia. Guadalajara, México: Barricadas en Acción.

Duchesne Winter, J. (2017). Invitación al Baile del Muñeco Máscara, pensamiento y territorio en el Amazonas. Bogotá: Aurora.

EFEverde, (2018). Los indígenas enseñan el "viaje" de la ayahuasca en el Foro Económico Latinoamericano. En El Espectador - jueves 12 de abril de 2018. (Consultado: 16 de marzo de 2018). Disponible en «https://www.elespectador. com/noticias/medio-ambiente/los-indigenas-ensenan-elviaje-de-la-ayahuasca-en-el-foro-economico-latinoamericanoarticulo-744811»

Guidieri, R. (1987). Cargaison. París: Seuil.

Rivera Cusicanqui, S. (2006). “Construcción de imágenes de indios y mujeres en la iconografía post-52: el miserabilismo en el 'Álbum de la Revolución'", en: S.R.C., Sociología de la imagen - Miradas ch'ixi desde la historia andina. Buenos Aires: Tinta Limón.

S. S. F. (2015). Laudato si' - Sobre el cuidado de la casa común. Bogotá: Instituto Misionero. 